\title{
Involvement of the glutamine RF-amide peptide and its cognate receptor GPR103 in prostate cancer
}

\author{
MOHAMED AB. KAWAN ${ }^{1 *}$, IOANNIS KYROU ${ }^{1-4^{*}}$, MANJUNATH RAMANJANEYA $^{1}$, KEVIN WILLIAMS $^{5}$, \\ JEYAROOBAN JEYANEETHI $^{6}$, HARPAL S. RANDEVA ${ }^{1-4^{* *}}$ and EMMANOUIL KARTERIS ${ }^{6^{* *}}$ \\ ${ }^{1}$ Translational and Experimental Medicine, Clinical Sciences Research Institute, Warwick Medical School, \\ University of Warwick, Coventry CV4 7AL; ${ }^{2}$ Warwickshire Institute for The Study of Diabetes, \\ Endocrinology and Metabolism (WISDEM), University Hospitals Coventry and Warwickshire NHS Trust, \\ Coventry CV2 2DX; ${ }^{3}$ Aston Medical Research Institute, Aston Medical School, Aston University, Birmingham B4 7ET; \\ ${ }^{4}$ Centre of Applied Biological and Exercise Sciences, Faculty of Health and Life Sciences, Coventry University, \\ Coventry CV1 5FB; ${ }^{5}$ Department of Urology, University Hospitals Coventry and Warwickshire NHS Trust, \\ Coventry CV2 2DX; ${ }^{6}$ Biosciences, Department of Life Sciences, Brunel University, Uxbridge, Middlesex UB8 3PH, UK
}

Received January 24, 2018; Accepted July 10, 2018

DOI: $10.3892 /$ or.2018.6893

\begin{abstract}
Glutamine RF-amide peptide (QRFP) belongs to the RFamide neuropeptide family, which is involved in a wide spectrum of biological activities, ranging from food intake and cardiovascular functioning to analgesia, aldosterone secretion, locomotor activity and reproduction. Recently, QRFP has been demonstrated to exert its effects by activating the G protein-coupled receptor GPR103. QRFP is expressed in the brain and peripherally in the adipose tissue, bladder, colon, testis, parathyroid and thyroid gland, as well as in the prostate gland. Following lung cancer, prostate cancer constitutes the second most frequently diagnosed cancer among men, whilst obesity appears to be a contributing factor for aggressive prostate cancer. In the present study, we sought to investigate the role of QRFP in prostate cancer, using two androgen-independent
\end{abstract}

Correspondence to: Dr Emmanouil Karteris, Biosciences, Department of Life Sciences, Brunel University, Uxbridge, Middlesex UB8 3PH, UK

E-mail: emmanouil.karteris@brunel.ac.uk

Professor Harpal S. Randeva, Warwickshire Institute for The Study of Diabetes, Endocrinology and Metabolism (WISDEM), University Hospitals Coventry and Warwickshire NHS Trust, Coventry CV2 2DX, UK

E-mail: harpal.randeva@warwick.ac.uk

"Joint senior authorship

${ }^{* *}$ Contributed equally

Abbreviations: GRFP, glutamine RF-amide peptide; GPR103, G protein-coupled receptor 103; GPCR, G protein-coupled receptor

Key words: glutamine RF-amide peptide, G protein-coupled receptor 103, prostate cancer, $\mathrm{G}$ protein-coupled receptor human prostate cancer cell lines (PC3 and DU145) as in vitro experimental models and clinical human prostate cancer samples. The expression of both QRFP and GPR103 at the gene and protein level was higher in human prostate cancer tissue samples compared to control and benign prostatic hyperplasia (BHP) samples. Furthermore, in both prostate cancer cell lines used in the present study, QRFP treatment induced the phosphorylation of ERK1/2, p38, JNK and Akt. In addition, QRFP increased cell migration and invasion in these in vitro models, with the increased expression of MMP2. Furthermore, we demonstrated that the pleiotropic adipokine, leptin, increased the expression of QRFP and GPR103 in PC3 prostate cancer cells via a PI3K- and MAPK-dependent mechanism, indicating a novel potential link between adiposity and prostate cancer. Our findings expand the existing evidence and provide novel insight into the implication of QRFP in prostate cancer.

\section{Introduction}

RFamide peptides comprise a family of neuropeptides which are characterized by a common carboxy-terminal motif consisting of an arginine (R) and an amidated phenylalanine (F) (1). Vertebrate RFamides are categorized into five groups, namely i) the neuropeptide FF (NPFF); ii) the prolactin-releasing peptide (PrRP); iii) the gonadotropin-inhibitory hormone $(\mathrm{GnIH})$; iv) the kisspeptin (also known as metastin); and v) the $26 \mathrm{RFa} / \mathrm{QRFP}$ group $(2,3)$. The latter was initially identified in frog brain (4), with the $\mathrm{N}$-extended longest form of the glutamine RF-amide peptide (QRFP) consisting of 43 amino acids, while due to several processing sites of this peptide a 26 (26RFa), 6 (26RFa20-26) and 9 (9RFa) amino acid form can also be produced (4-7). QRFP has been identified as the cognate ligand of the previously identified human orphan $\mathrm{G}$ protein-coupled receptor (GPCR) GPR103 (8,9). Notably, GPR103 shares 48 and 47\% protein sequence homology with the two orexin receptors, OX1R and OX2R, respectively (8). 
In the human brain, the QRFP gene has been found to be almost exclusively expressed in certain hypothalamic areas/nuclei, such as the lateral hypothalamic area (LHA), the ventromedial hypothalamic nucleus (VMH), the arcuate nucleus (Arc) and the paraventricular nucleus (PVN), which are involved in the regulation of the feeding behaviour $(5,7)$. Outside the central nervous system (CNS), in humans, QRFP is also expressed in various endocrine glands (e.g., in the testis and the adrenal, thyroid and parathyroid glands), as well as in the prostate gland, where its expression is higher compared to that in the hypothalamus $(7,8,10)$. According to its widespread expression, QRFP appears to be implicated in a number of biological functions/systems, including the regulation of feeding behaviour (11) and the control of the gonadotropic axis $(12,13)$. Notably, the central administration of QRFP in mice has been demonstrated to result in increased arterial blood pressure (BP) and heart rate (HR), as well as in increased stress activity levels based on grooming behaviour (6).

In addition, 26RFa has been shown to be expressed in human prostate cancer and to stimulate the neuroendocrine differentiation and migration of androgen-independent DU145 prostate cancer cells (14). Overall, prostate cancer is the fourth most common cancer globally, whilst it constitutes a leading cause of cancer-related mortality and the second most frequently diagnosed cancer among men, following only lung cancer $(15,16)$. More than 1.1 million new prostate cancer cases were diagnosed worldwide in 2012 (17), whilst the global burden of prostate cancer is expected to keep increasing in the next decades in parallel to the increasingly ageing population (18). Notably, androgen deprivation/ablation therapy is the mainstay treatment option for advanced prostate cancer, which is initially effective in slowing the disease progression, since androgens stimulate prostate cancer growth (19). However, prostate cancer often progresses eventually to an androgen-independent state which is characterized by a poor prognosis (19).

Given the existing evidence indicating that $26 \mathrm{RFa}$ and GPR103 are present in prostate carcinomatous foci which exhibit neuroendocrine differentiation (14), in the present study, we aimed to further explore the role of both QRFP and GPR103 in prostate carcinogenesis by studying their expression in human prostate cancer samples and using two androgen-independent prostate cancer cells lines (PC3 and DU145) as in vitro experimental models.

\section{Materials and methods}

Prostate cancer cell lines cultures. The human androgen-independent prostate cancer cell lines, DU145 and PC3, were purchased from the American Type Culture Collection (ATCC, Manassas, VA, USA) and were cultured in $75 \mathrm{~cm}^{2}$ cell culture flasks, in Ham's F12 (Sigma-Aldrich, Gillingham, UK) and RPMI-1640 media (Invitrogen, Paisley, UK), respectively, supplemented with $10 \%$ fetal calf serum (FCS) (Thermo Fisher Scientific, Loughborough UK) and $5 \mathrm{ml}$ of $100 \mathrm{X}$ antibiotic-antimycotic (Thermo Fisher Scientific). All flasks were incubated in a humidified incubator at $37^{\circ} \mathrm{C}$ in $5 \% \mathrm{CO}_{2}$, and were routinely passaged at approximately $70-80 \%$ confluency. Of note, although the PC3 cell line has been assigned twice under NCBI (catalogue number C427), this does not affect the outcomes of our study.
In vitro treatments. For the phosphorylation analyses, both the PC3 and DU145 cell lines were treated with QRFP (Phoenix Peptides, Burlingame, CA, USA; $100 \mathrm{nM}$ ) for up to $60 \mathrm{~min}$ at the following time-points: 0 (no supplement), 5, 15, 30 and $60 \mathrm{~min}$. For the cell invasion assays, cells were treated with QRFP for $8 \mathrm{~h}$ at 1, 10 and $100 \mathrm{nM}$. Epidermal growth factor (EGF; Sigma-Aldrich), at $50 \mathrm{ng} / \mathrm{ml}$ was also used as a positive control. For the same experiment, we used the PI3K inhibitor, LY294002 (Sigma-Aldrich), and the MAPK inhibitor, U0126 (Sigma-Aldrich), both at $10 \mathrm{mM}$, in the presence or absence of QRFP. For the effects of adipokines, the PC3 cells were treated with leptin $(100 \mathrm{nM})$, adiponectin $(10 \mathrm{nM})$, and chemerin (1 nM) (R\&D Systems, Abingdon, UK) for $24 \mathrm{~h}$ prior to assessing the levels of QRFP and GP103 by RT-qPCR. The same concentrations of LY294002 and U0126 were used.

Prostate tissue samples. Human prostate tissue samples (benign prostatic hyperplasia, $n=5$ and malignant, $n=5$ ) were obtained from men undergoing various prostate procedures, such as radical retro-pubic prostatectomy (RRP), transurethral prostate resection (TURP) or transrectal ultrasound (TRUS) and prostate biopsy, at the University Hospitals Coventry and Warwickshire (UHCW) NHS Trust (date range of recruitment/sample collection: November, 2010 to October, 2015). The present study was approved by the National Research Ethics Committee and the Research and Development department of the UHCW NHS Trust (16/11/2010-1/10/2015) and was conducted according to the principles of good clinical practice and the recommendations of the Declaration of Helsinki. Men undergoing prostate surgery for either benign or malignant conditions or undergoing a prostate biopsy for suspected cancer either with an elevated age-specific PSA or with an abnormal prostate investigation were approached for potential inclusion into the study. Patients were presented with a full explanation of the nature of the study, including the potential benefits and risks of taking part. All patients recruited into the study provided informed signed consent. All collected prostate tissue samples for the present study were immediately snap-frozen in liquid nitrogen and stored at $-80^{\circ} \mathrm{C}$ until use. Radical prostatectomy specimens were removed en bloc and were formalin-fixed, paraffin-embedded as per standard hospital practice. The tissue samples were available for use in the present study after the hospital pathologist had issued a final pathology report on each specimen for grading/staging purposes.

Western blot analysis. Cell and tissue lysates were extracted using RIPA cell lysis buffer (Sigma-Aldrich) and a cell scraper or a homogeniser respectively, according to the manufacturers' guidelines. Protein concentrations were determined calorimetrically using the bicinchoninic acid (BCA) protein assay kit according to manufacturer's instructions (Sigma-Aldrich). Samples were subsequently prepared for gel electrophoresis prepared by the addition of $2 \mathrm{X}$ Laemmli buffer (Sigma-Aldrich), and boiled for $5 \mathrm{~min}$. The proteins were separated by SDS-PAGE 8-10\%, and transferred to polyvinylidene difluoride (PVDF) membranes at $100 \mathrm{~V}$ for $1 \mathrm{~h}$ in a transfer buffer containing $20 \mathrm{mM}$ Tris, $150 \mathrm{mM}$ glycine and $20 \%$ methanol. PVDF membranes were blocked in Tris-buffered saline (TBS) containing 0.1\% Tween-20 and 
$5 \% \mathrm{BSA}$ for 1 or $2 \mathrm{~h}$ and were incubated with the relevant anti-rabbit primary antibodies overnight at $4^{\circ} \mathrm{C}$. On the following day, these membranes were washed thoroughly four times in $60 \mathrm{~min}$ with TBS- $0.1 \%$ Tween, before incubation with the appropriate secondary anti-rabbit antibody buffer (1:2,000 dilution; Sigma-Aldrich), for $1 \mathrm{~h}$ at room temperature. The antibodies (all anti-rabbit) used were: GPR103 (1:3,000 dilution; Acris Antibodies, Herford, Germany), QRFP-43 (1:4,000 dilution; Phoenix Pharmaceuticals, Belmont, CA), ERK1/2, p38, JNK, AKT (all 1:1,000 dilution; both phospho and total; Cell Signaling Technology, Leiden, Netherlands), MMP2 (1:1,000 dilution) and GAPDH (1:5,000 dilution; Sigma-Aldrich, Gillingham, UK) at concentrations recommended by the manufacturers. Antibody complexes were visualized using ECL-Plus (Thermo Fisher Scientific), according to the manufacturer's instructions. The appropriate positive and negative controls were used. All densities were determined using a scanning densitometer coupled to scanning ImageQuant ${ }^{\mathrm{TM}}$ software 7.0 (GE Healthcare Life Sciences, Little Chalfont, UK).

RNA isolation, cDNA synthesis and reverse transcriptionquantitative PCR (RT-qPCR). Total RNA was extracted from the human prostate cancer tissue samples and cell lines using the Qiagen RNeasy plus Mini kit (Qiagen, Manchester, UK). RNA samples were then treated by RNase-free DNase to eliminate genomic DNA contamination. The extracted RNA purity and quantity was assessed by a NanoDrop spectrophotometer (Thermo Fisher Scientific). In addition, $1 \mu \mathrm{g}$ of total RNA was reverse transcribed into cDNA, by using Moloney Murine Leukemia Virus (M-MuLV) Reverse Transcriptase and random hexamers primers (Thermo Fisher Scientific).

The relative expression of the genes of interest was assessed by quantitative polymerase chain reaction (qPCR) on an ABI7500 instrument (Applied Biosystems; Thermo Fisher Scientific, Inc., Waltham, MA, USA) using SYBR ${ }^{\circledR}$-Green-PCR reaction mixture (Sigma Aldrich; Merck KGaA, Darmstadt, Germany). The primers used in the present study were as follows: for QRFP sense, 5'-AGGCAGGACGAAGGCAGT GA-3' and antisense, 5'-GACCGAAGCGGAAGCTGA AG-3'; for GPR103 sense, 5'-CCAGTCTACCGCTGTTGT GA-3' and antisense 5'-GCCAGACCACACCTAGCATT-3' and; for GAPDH (as a reference gene) sense 5'-TGCACC ACCAACTGCTTA-3' and antisense, 5'-GATGCAGGGATG ATGTTC-3'. The thermocycling conditions were as follows: Hotstart $95^{\circ} \mathrm{C}$ for $10 \mathrm{~min}\left(1\right.$ cycle); amplification at $95^{\circ} \mathrm{C}$ for $15 \mathrm{sec}$ followed by at $60^{\circ} \mathrm{C}$ for $60 \mathrm{sec}(40$ cycles) and dissociation curve at $60-95^{\circ} \mathrm{C}$ for $1 \mathrm{~min}(1 \mathrm{cycle})$. Negative controls for all the reactions included preparations lacking cDNA or RNA-lacking reverse transcriptase in place of the cDNA. RNAs were assayed from two to three independent biological replicates. RNA levels were expressed as a 'relative quantification' using the housekeeping gene GAPDH value. The $2^{-\Delta \mathrm{Ct}}$ method was employed for comparing relative expression results between treatments in qPCR (20).

$x$ CELLigence migration and invasion assays. Real-time cell proliferation, migration and invasion experiments were performed using the xCELLigence system (ACEA Biosciences, San Diego, CA, USA), consisting of the Real-Time Cell
Analyzer Dual Purpose (RTCA-DP) instrument placed in a humidified incubator maintained at $5 \% \mathrm{CO}_{2}$ and $37^{\circ} \mathrm{C}$, and cell invasion and migration (CIM) plates for cell migration and invasion according to the manufacturer's protocol. The RTCA software 1.2 (Roche, Basel, Switzerland) monitored cell proliferation, reporting changes in the Cell Index (CI) following the treatment of the cells.

Statistical analysis. All results presented are expressed as the mean \pm SD. A Student's t-test was used to difference between 2 groups. Comparisons between more than 2 groups were analysed by ANOVA (non-parametric) analysis followed by post hoc Tukey's multiple comparison test. Values were considered to be statistical significance set at either $\mathrm{P}<0.05, \mathrm{P}<0.01$ or $\mathrm{P}<0.001$. All statistical analyses were performed using Graph Pad software 5.0 (La Jolla, CA, USA).

\section{Results}

Expression of QRFP and GPR103 in human prostate cancer clinical samples and cell lines. QRFP and GPR103 mRNA levels in human prostate tissue samples were determined by RT-qPCR, which revealed that the gene expression of both QRFP and GPR103 was significantly higher in the prostate cancer samples $(n=5)$ compared to the samples from benign prostate hyperplasia patients $(\mathrm{BPH} ; \mathrm{n}=5)($ Fig. 1A). Furthermore, this statistically significant difference was also detected at the protein level, with both QRFP and GPR103 being significantly upregulated in prostate cancer tissue samples compared to BPH (Fig. 1B). Using human prostate cancer tissue lysate from one of the patients described above as a positive control, we also revealed that both the androgen-insensitive prostate cancer cell lines (PC3 and DU145), which we used for in vitro experiments in the present study, expressed QRFP and GPR103 at the protein level (Fig. 1C).

Effects of QRFP on the phosphorylation status of prostate cancer cell lines. To examine the signalling pathways which may be involved in the effects of QRFP on prostate cancer cells, the phosphorylation status of ERK1/2,p38, JNK and Akt was assessed in the two androgen-insensitive prostate cancer cell lines of the present study following QRFP treatment. The PC3 and DU145 cells were treated with QRFP (100 nM) for up to $60 \mathrm{~min}(0,5,15,30$ and 60 min time-points). This QRFP treatment resulted in the statistically significant activation of ERK1/2 in the treated PC3 and DU145 cells at 5 min $(\mathrm{P}<0.01$ and $\mathrm{P}<0.001$, respectively) (Fig. $2 \mathrm{~A}$ and $\mathrm{B}$ ). In addition, the significantly increased p38 phosphorylation was observed at different time-points in these two cell lines. In PC3 cells, the significant activation of p38 was noted at $30 \mathrm{~min}(\mathrm{P}<0.01)$, as well as at 15 and $60 \mathrm{~min}(\mathrm{P}<0.05)$, compared to the basal levels. In DU145 cells, maximal activation of $\mathrm{p} 38$ was reached at 60 min $(\mathrm{P}<0.01)$ compared to basal levels (Fig. $2 \mathrm{C}$ and $\mathrm{D})$. Furthermore, maximal JNK phosphorylation occurred at 30-60 min in PC3 cells $(\mathrm{P}<0.05$; Fig. $2 \mathrm{E})$, whilst in DU145 cells, a biphasic response was noted at 5 and $60 \mathrm{~min}(\mathrm{P}<0.01$ and $\mathrm{P}<0.05$, respectively; Fig. $2 \mathrm{~F}$ ). Finally, Akt phosphorylation increased significantly in PC3 cells from 15 to $60 \mathrm{~min}$ of QRFP treatment $(\mathrm{P}<0.01$; Fig. $2 \mathrm{G})$, whilst a similar trend was also noted in the QRFP-treated DU145 cells, with maximal 
A

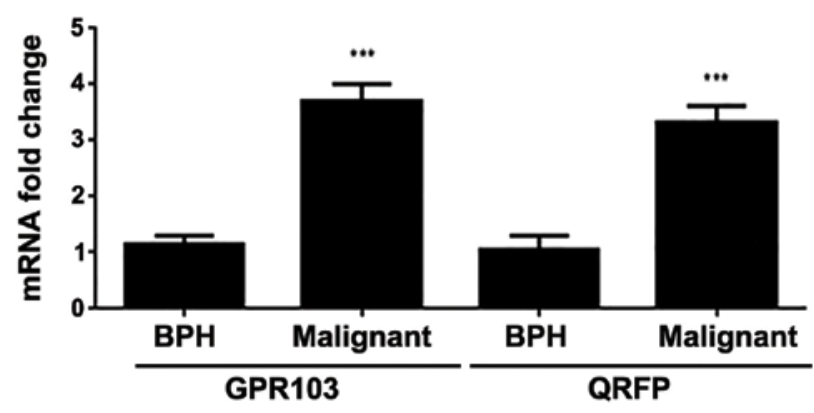

B
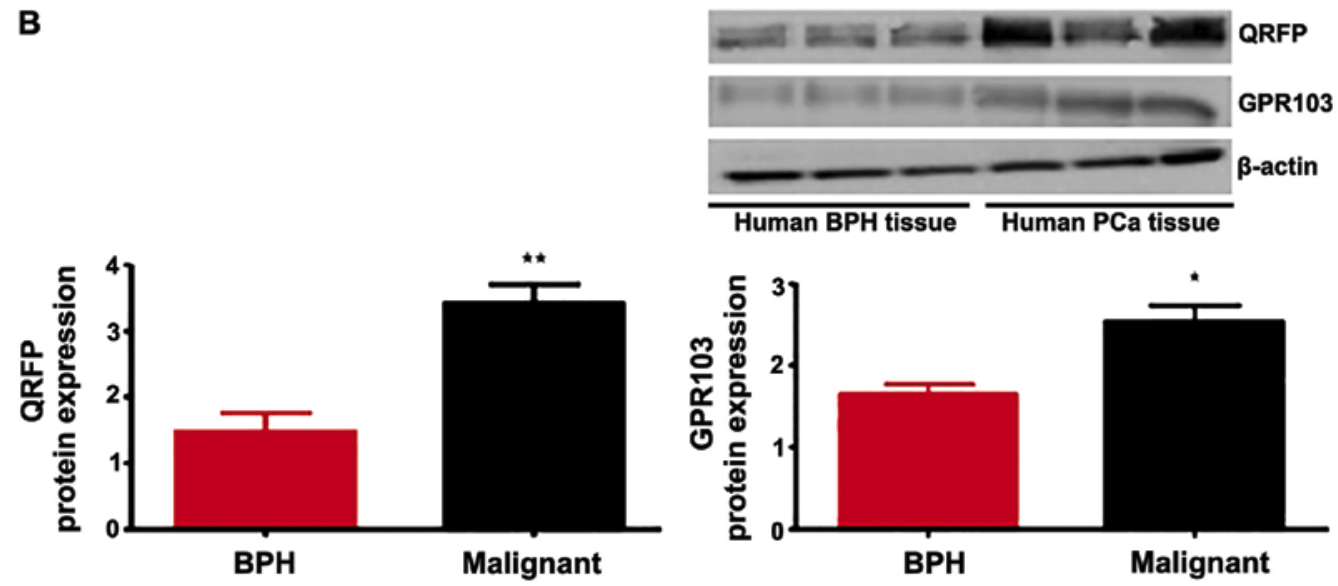

C

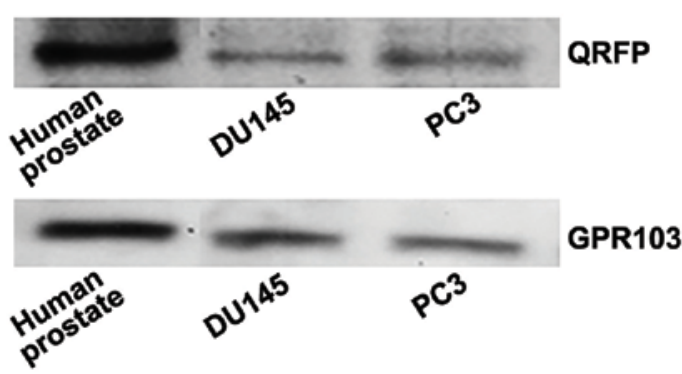

Figure 1. (A) QRFP and its cognate receptor GPR103 mRNA expression in BHP and prostate cancer (malignant) samples $\left({ }^{* * *} \mathrm{P}<0.001 ; \mathrm{n}=5\right.$ per group mean \pm SD). (B) Representative western blots for QRFP and GPR103 and quantification of western blotting indicating significant protein expression levels of QRFP (14 kDa) and GPR103 (49 kDa) in human prostate cancer tissue (malignant) compared to BHP $\left({ }^{* *} \mathrm{P}<0.01,{ }^{*} \mathrm{P}<0.5\right.$; $\mathrm{n}=5$ per group; mean $\pm \mathrm{SD}$ ). (C) Western blotting demonstrating that both the androgen-independent human prostate cancer cell lines (PC3 and DU145) used in the in vitro experiments of our study express QRFP and GPR103 at the protein level. Human prostate tissue lysate was used as a positive control. QRFP, glutamine RF-amide peptide; BHP, benign prostatic hyperplasia.

Akt phosphorylation at 30 and $60 \mathrm{~min}(\mathrm{P}<0.05$ and $\mathrm{P}<0.01$, respectively; Fig. $2 \mathrm{H}$ ).

To demonstrate the specificity of these responses, we also employed a siRNA approach for the GPR103 receptor, using the PC 3 cells and Akt phosphorylation as our experimental paradigm. Following siRNA transfection, the GPR103 mRNA levels significantly decreased in the transfected PC 3 cells with increasing concentrations of siRNA, with the maximum reduction observed at the $10 \mathrm{nM}$ siRNA concentration. Furthermore, QRFP-induced Akt phosphorylation was significantly decreased in the PC3 cells transfected with GPR103 siRNA compared to the control PC3 cells (data not shown).

Effects of QRFP on cell migration and invasion in prostate cancer cell lines. Following the effects of QRFP treatment on the phosphorylation of key kinases in the two prostate cancer cell lines in our study, we hypothesised that this would further affect cell migration and invasion. To explore such effects, we used the xCELLigence system, and EGF $50 \mathrm{ng} / \mathrm{ml}$ as a positive control.

Our experiments revealed that there was a significant and concentration-dependent increase in cell migration $(10 \mathrm{nM}$, $\mathrm{P}<0.05$; and $100 \mathrm{nM}, \mathrm{P}<0.01$, compared to basal) in QRFP-treated PC3 cells at $8 \mathrm{~h}$ of treatment (Fig. 3A). In DU145 cells statistical significance compared to basal levels was reached only at the highest QRFP concentration (100 nM; P<0.01; Fig. 3C). In both cell lines, only a PI3K inhibitor (LY294002; $10 \mathrm{mM}$ ) significantly inhibited the effect of the applied QRFP treatment. The use of a MAPK inhibitor (U0126; $10 \mathrm{mM}$ ) revealed a similar trend; however its effects did not reach to statistical significance in either PC3 (Fig. 3B) or DU145 (Fig. 3D) QRFP-treated cells. 
A
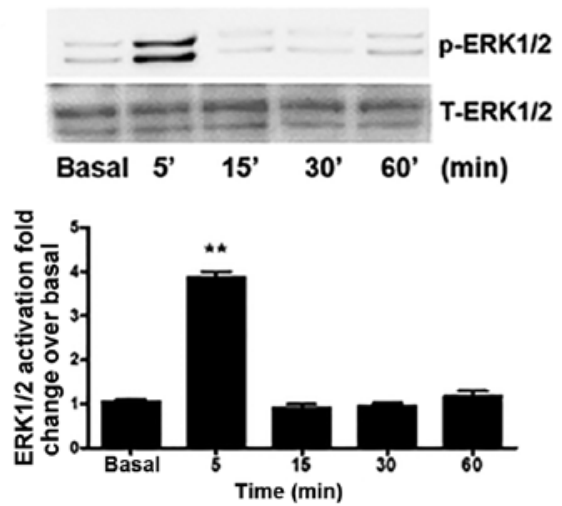

C
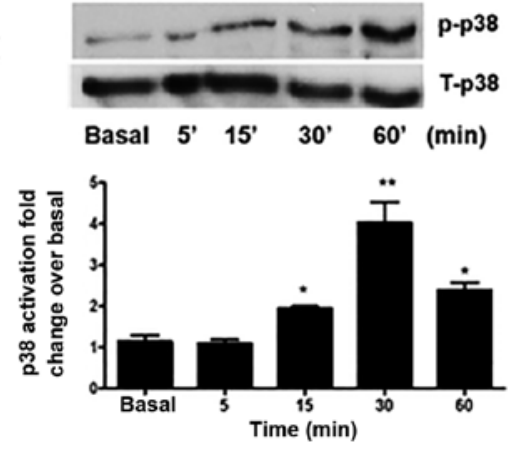

E
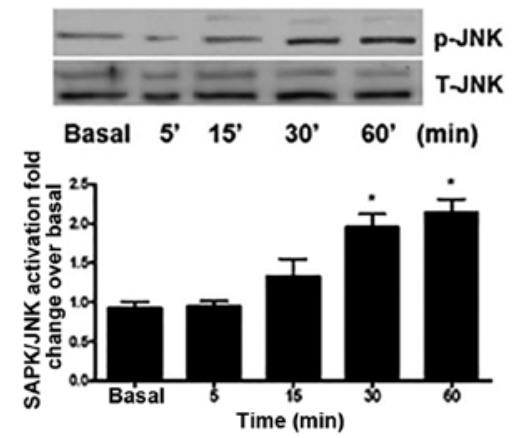

G
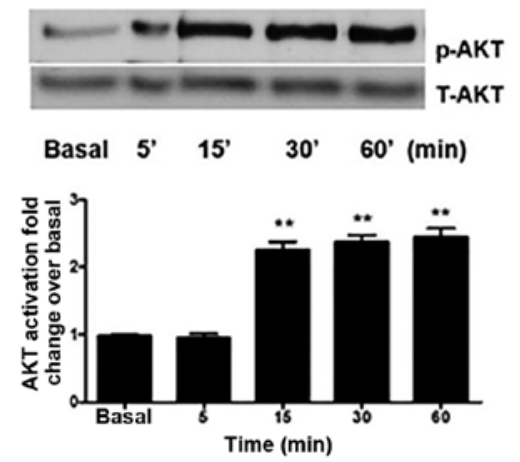

B
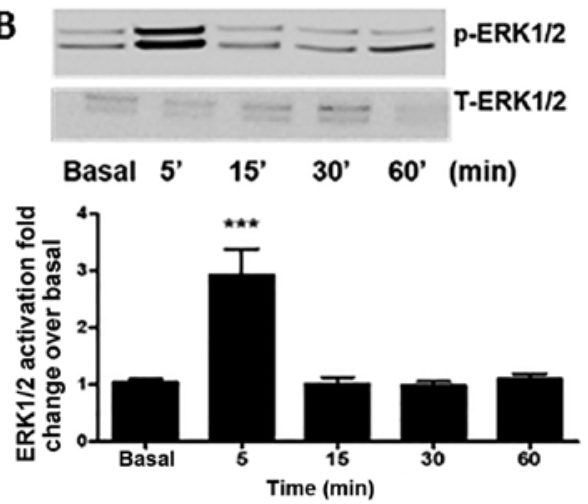

D
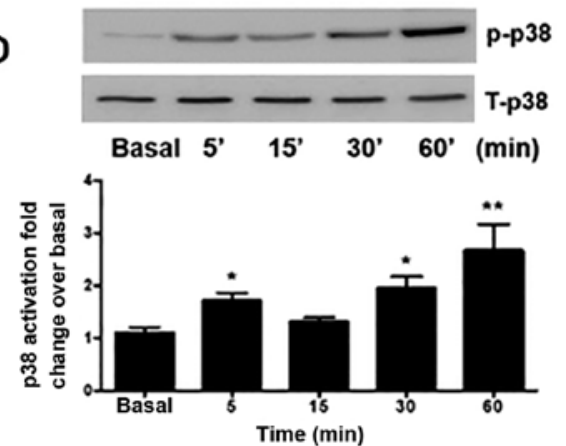

$\mathbf{F}$
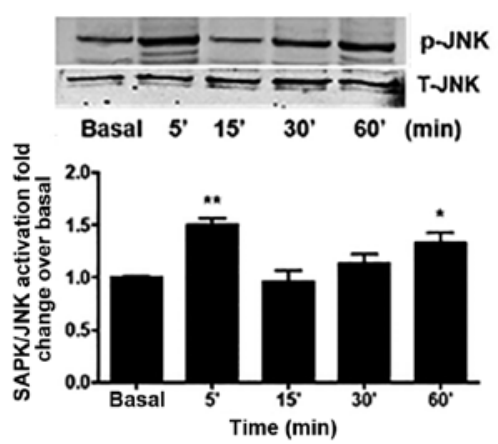

H
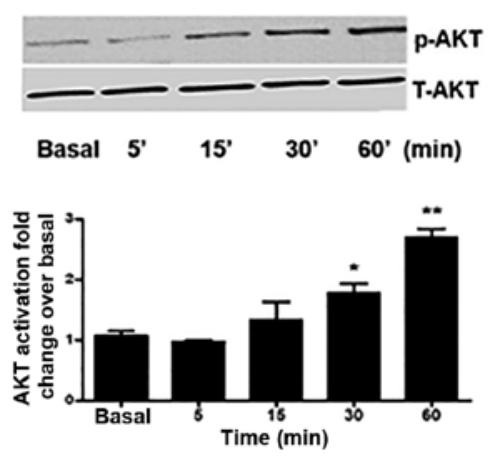

Figure 2. Representative western blots and quantitative analysis of signalling pathway-related molecules in androgen-independent (A, C, E and G) PC3 and (B, D, F and H) DU145 prostate cancer cells, demonstrating significantly increased phosphorylation status of (A and B) ERK1/2, (C and D) p38, (E and F) JNK, and $(\mathrm{G}$ and $\mathrm{H})$ Akt. Cells were treated for 5, 15, 30 and 60 min with $100 \mathrm{nM} \mathrm{QRFP}\left({ }^{* * * *} \mathrm{P}<0.001,{ }^{* *} \mathrm{P}<0.01,{ }^{*} \mathrm{P}<0.05\right)$.

Similarly, $8 \mathrm{~h}$ of QRFP treatment significantly increased the invasive ability of $\mathrm{PC} 3$ cells $(10 \mathrm{nM} ; \mathrm{P}<0.05$ and $100 \mathrm{nM}$; $\mathrm{P}<0.01$, compared to basal; Fig. 4A). In DU145 cells, a significant effect on invasion was noted only at the highest used QRFP concentration (100 nM; P<0.05, compared to basal; Fig. 4B). Despite the effects of QRFP on cell migration and invasion, there was no apparent effect on overall cell proliferation in either cell line (data not shown).
Since there is strong evidence of the role of matrix metalloproteinases (MMPs) in the remodelling, including angiogenesis, of the extracellular matrix (ECM), in the present study, we also tested the hypothesis that MMP2 is involved in the effects of cellular invasion. The PC 3 and DUP145 cells were incubated with $100 \mathrm{nM}$ QRFP for up to $12 \mathrm{~h}$ and the expression of MMP2 was assessed at regular time-points $(1,2,4,6,10$ and $12 \mathrm{~h})$ by western blotting. In PC 3 cells, QRFP 
A

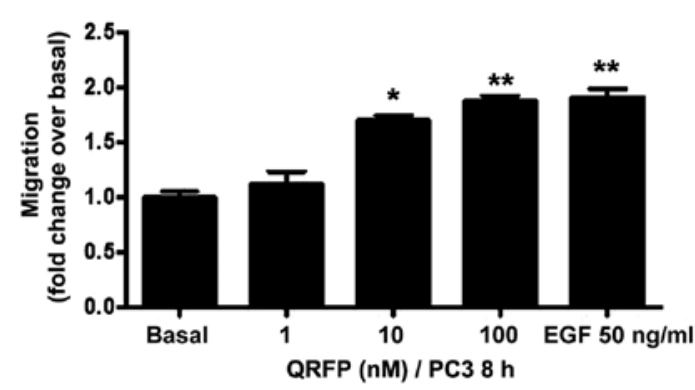

C

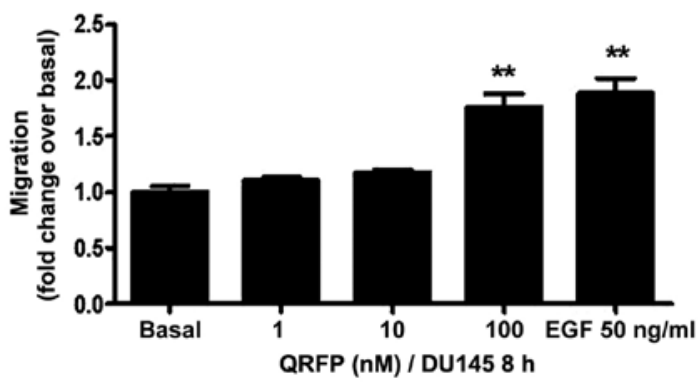

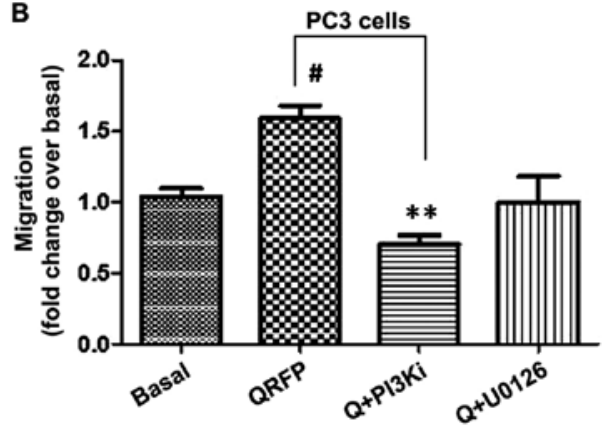

D

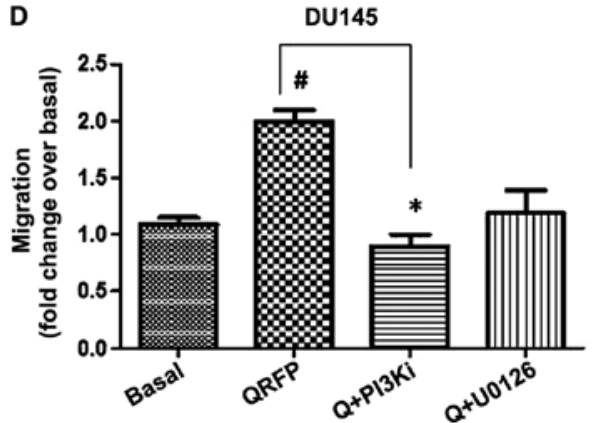

Figure 3. The effect of QRFP treatment on the cell migration of (A) PC3 and (C) DU145 cell lines using the xCELLigence system. Both cell lines were treated in a concentration-dependent manner $(1,10$ and $100 \mathrm{nM})$ for $8 \mathrm{~h}$. Treatment with the epidermal growth factor (EGF; $50 \mathrm{ng} / \mathrm{ml}) \mathrm{was}$ used as positive control. Results were calculated by the xCELLigence Real-Time Cell Analyzer (RTCA) software ( ${ }^{*} \mathrm{P}<0.05$ and ${ }^{* *} \mathrm{P}<0.01$ compared to basal, $\mathrm{n}=5$; mean $\pm \mathrm{SD}$ ). (B and D) The effects of QRFP treatment (100 nM for $8 \mathrm{~h}$ ) in the presence or absence of PI3K (PI3Ki:LY294002; $10 \mathrm{mM}$ ) and MAPK/ERK (UO126; $10 \mathrm{mM}$ ) inhibitors on migration signalling pathways in PC 3 and DU145 cells. Data were evaluated using the xCELLigence RTCA software $\left({ }^{*} \mathrm{P}<0.05\right.$ compared to basal; ${ }^{*} \mathrm{P}<0.05$ and ${ }^{* *} \mathrm{P}<0.01$ compared to QRFP treatment; $\mathrm{n}=5$; mean $\pm \mathrm{SD}$ ).

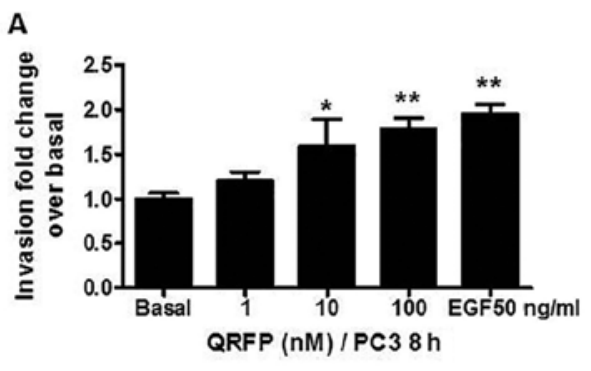

C

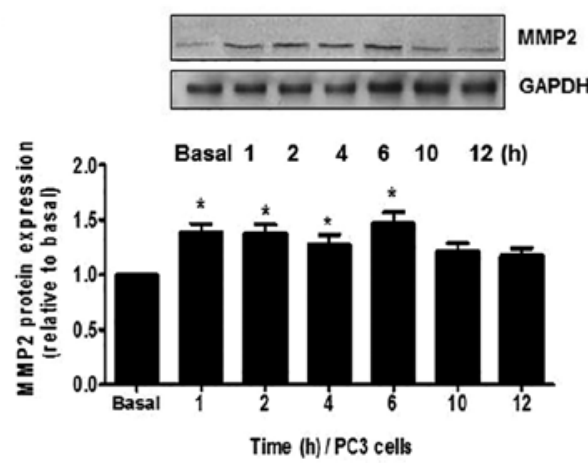

B

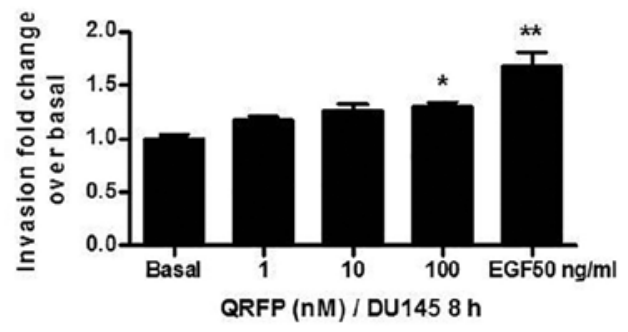

D
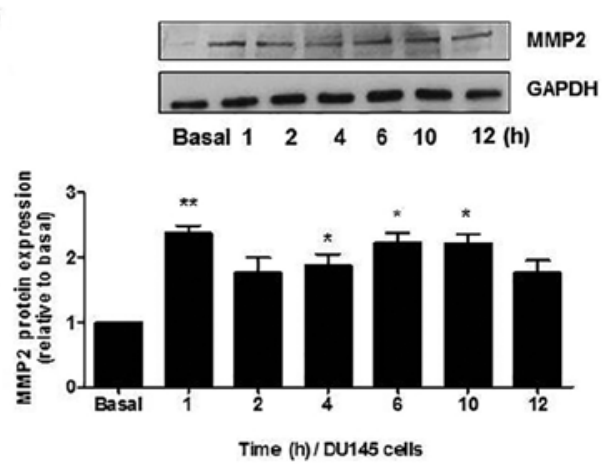

Figure 4. Effect of QRFP treatment on the cell invasion of (A) PC3 and (B) DUP145 cells using the xCELLigence system. Both cell lines were treated in a concentration-dependent manner $(1,10$ and $100 \mathrm{nM})$ for $8 \mathrm{~h}$. Treatment with the epidermal growth factor (EGF; $50 \mathrm{ng} / \mathrm{ml})$ was used as positive control. Results were calculated by the xCELLigence Real-Time Cell Analyzer (RTCA) software ( $\left(\mathrm{P}<0.05,{ }^{* *} \mathrm{P}<0.01, \mathrm{n}=5\right.$; mean $\left.\pm \mathrm{SD}\right)$. (C and D) Representative western blots and quantification of the effect of treatment with $100 \mathrm{nM}$ QRFP at varying time-points (1, 2, 4, 6, 10 and $12 \mathrm{~h}$ ) on the expression of MMP2 protein in (C) PC3 and (D) DUP145 prostate cancer cells. Data presented as the mean $\pm \mathrm{SD}$ from three independent experiments. ${ }^{*} \mathrm{P}<0.05,{ }^{* *} \mathrm{P}<0.01$ compared to basal expression. GAPDH used as a loading control.

treatment significantly induced MMP2 protein expression at 1 to $6 \mathrm{~h}$ (all P-values <0.05, compared to basal; Fig. 4C). In
QRFP-treated DUP145 cells, the highest significant increase was noted at $1 \mathrm{~h}(\mathrm{P}<0.01)$, whilst significantly increased 
A

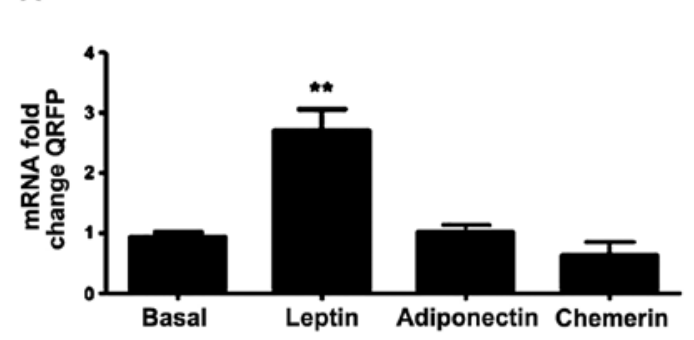

C

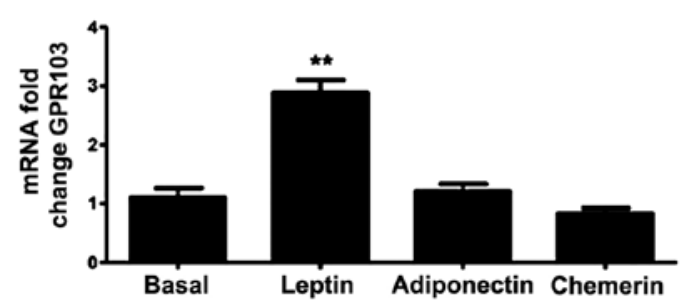

B

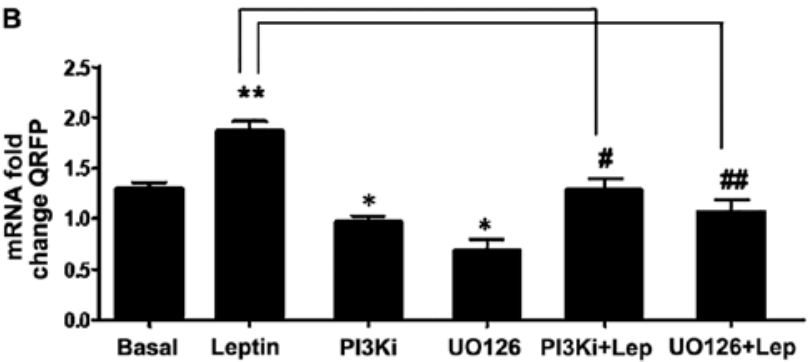

D

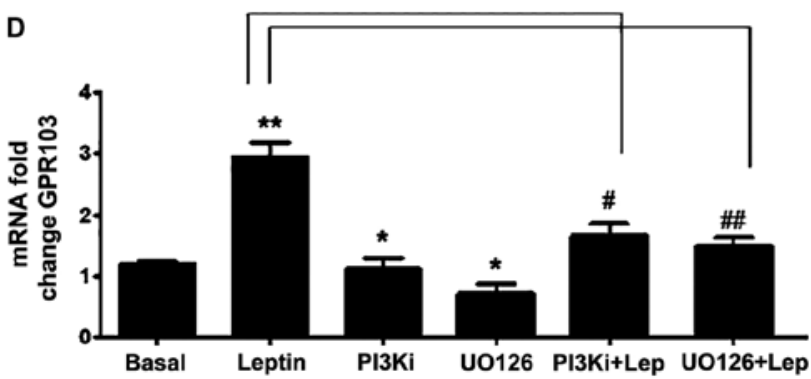

Figure 5. Effects on (A) QRFP and (C) GPR103 gene expression in the PC3 prostate cancer cell line following $24 \mathrm{~h}$ of treatment with leptin (100 nM) or adiponectin $(10 \mathrm{nM})$ or chemerin $(1 \mathrm{nM})$. Data presented as the mean \pm SD. Only the applied leptin treatment significantly increased QRFP and GPR103 mRNA levels at $24 \mathrm{~h}\left({ }^{* *} \mathrm{P}<0.01\right.$, compared to basal; experiment performed in triplicate). (B and D) Effects of PI3K (PI3Ki: LY294002) and MAPK (UO126) inhibitors in the presence or absence of leptin on (B) QRFP and (D) GPR103 gene expression (data presented as the mean \pm SD; ${ }^{*} \mathrm{P}<0.05$, ${ }^{* *} \mathrm{P}<0.01$ compared with basal levels; ${ }^{\#} \mathrm{P}<0.05$ and ${ }^{\# \#} \mathrm{P}<0.01$ compared to leptin treatment; the experiment was performed in triplicate).

levels were also documented at 4 to $10 \mathrm{~h}$ (all P-values $<0.05$, compared to basal; Fig. 4D).

Effects of leptin on QRFP and GPR103 gene expression in PC3 prostate cancer cells. Several studies have revealed an association between adipokines with prostate cancer progression. Thus, in this study, we also investigated whether QRFP and GPR103 gene expression in PC3 cells is regulated by certain key adipokines, namely leptin, adiponectin, and chemerin. Based on these experiments, only leptin significantly induced the expression of QRFP and GPR103 (Fig. 5A and C). This leptin-induced effect was time-dependent with a significant increase at 12 and $24 \mathrm{~h}$ (data not shown). Using specific inhibitors of PI3K (LY294002) and MAPK (U0126), we were also able to demonstrate that this leptin-induced effect was mediated via the PI3K and MAPK pathways (Fig. 5B and D).

\section{Discussion}

In the present study, we revealed that QRFP and its cognate receptor GPR103 were expressed in two androgen-independent human prostate cancer cell lines (PC3 and DU145), and that their expression was upregulated in human prostate cancer tissue samples compared to that in samples from benign prostate hyperplasia patients. These findings were in line with the data from Alonzeau et al (14), indicating that 26RFa was expressed in human prostate cancer, stimulating the neuroendocrine differentiation and migration of the DU145 cells. Based on these findings, we could not exclude the autocrine effects of this peptide, along with QRFP acting in an endocrine manner.

Our data also revealed that QRFP induced the phosphorylation of ERK1/2, p38, JNK and Akt in both prostate cancer cell lines used in the present study. It is already known that the MAPK regulates different cellular processes in prostate cancer, and that this signalling pathway is overexpressed in human prostate cancer compared to normal prostate tissue $(21,22)$. Autocrine and paracrine-acting growth factors can induce the increased expression of the Ras/Raf/MEK/ERK pathway, which has been associated with progressive prostate cancer (21). Furthermore, Ras signalling has been implicated in cancer cell invasion and metastasis, whilst the activation of the EGFR-ERK1/2 pathway promotes the migration and invasion of prostate cancer cells (23). Conversely, there are data indicate the activated ERK-dependent apoptosis of prostate cancer cell lines (24). It should also be noted that, Ras/Raf/MEK/ERK levels are differentially expressed amongst cancers (25). Hence, while it is plausible that the activation of the Ras/Raf/MEK/ERK cascade could contribute to prostate cancer development, further research is required to elucidate these mechanisms in androgen-independent prostate cancer lines which exhibit low expression levels of this cascade.

Unlike ERK1/2, p38 exhibits weak activation by mitogens, although it is strongly activated in response to various stressors, including inflammatory cytokines, UV radiation, and osmotic and heat shock (26). Notably, TNF $\alpha$ (a pro-inflammatory cytokine which is known to activate the MAPK stress response) has been shown to induce the apoptosis of the androgen-dependent LNCaP prostatic cancer cell line, but not that of androgen-independent PC3 cells, while p38 appears to exert protective effects against this TNF $\alpha$-induced apoptosis of LNCaP cells (27). Of note, the activation of $\mathrm{p} 38$ in prostate cancer may be a result of upregulated upstream kinases (MKK3/6) combined with downregulated MAPK phosphatases (28-30). Furthermore, p38 phosphorylation has been demonstrated in prostate cancer cell lines exposed to toxic agents, and this activation has been 
implicated in apoptosis $(31,32)$. Furthermore, it has been demonstrated that prostate cancer cell invasion was mediated via the p38 MAPK pathway, leading to phosphorylation of the heat shock protein 27 (HSP27) that in turn regulated MMP2 activation and cell invasion (33). In addition, Chen et al (34) revealed that the stimulation of the $\mathrm{G}$ protein-coupled $\mathrm{P} 2 \mathrm{Y}$ purinoceptor (metabotropic GPCR family) can induce prostate cancer cell invasion, which was regulated via the activation of the p38 pathway (34). It becomes evident that the activation of p38 plays a significant role in prostate cancer, and additional research is clearly needed to further explore the exact implications of the QRFP-induced p38 phosphorylation that was observed in the two androgen-independent prostatic cancer cell lines in the present study.

Furthermore, in the present study, we revealed the QRFP-mediated the activation of the JNK pathway in androgen-independent prostate cancer cells (PC3 and DU145). It is known that JNK is activated by certain growth factors and stressors (e.g., UV radiation) (35). In turn, this JNK activation frequently results in cell death via the activation of the mitochondrial apoptotic pathway in various cell types, including prostate cancer PC3 and DU145 cells, where JNK-initiated Fas-mediated apoptotic signals are considered to play a significant role in chemosensitivity $(35,36)$. It has also been revealed that, depending on the cell type and stimulus, JNK can activate several transcription factors (e.g., c-Jun, c-Fos, Elk-1, c-My, ATF-2 and p53), as well as various members of the Bcl-2 family $(37,38)$. JNK appears to regulate apoptosis via two distinct mechanisms: i) By promoting the phosphorylation of c-Jun and ATF-2 which results in the activation of AP-1 and the expression of Fas/FasL signalling pathway-related proteins, which further mediates the activation of certain caspases (caspase- 8 and -3 ) that trigger apoptosis; and ii) by mediating the phosphorylation of the anti-apoptotic proteins, $\mathrm{Bcl}-2 / \mathrm{Bcl}-\mathrm{xL}$, thus altering mitochondrial membrane potential and resulting in the release of cytochrome $c$ and the activation of caspase-9 and -3 to induce apoptosis (39).

In the present study, we also observed a marked promoting effect of QRFP on the activation of Akt signalling in both human prostate cell lines used, with a higher degree of phosphorylation in PC3 compared to DU145 cells. The latter finding may be attributed to the higher expression of $\mathrm{Akt}$ in PC3 cells (40). Using siRNA for the cognate GPR103 receptor, we further demonstrated that the QRFP-induced response was receptor-specific. Notably, the Akt signalling pathway can be activated by several cytokines, growth factors and oncogenes (41), whilst the phosphorylation of PI3K/Akt may contribute to the induction of tumour invasiveness and cancer development. The PI3K/Akt pathway activation has been more frequently associated with prostate cancer progression toward resistant/metastatic disease (42). Therefore, it has been considered that the PI3K/Akt pathway plays a role in the progression of prostate cancer, with the inhibition of the Akt pathway significantly affecting the EGFR-induced prostate cancer cell migration (43).

Collectively, the PI3K/Akt/mTOR signalling pathway has been revealed to regulate multiple cellular processes, such as cell survival, metabolism, proliferation, migration and angiogenesis. Accordingly, the ERK and PI3K/Akt pathways are critical for the regulation of cancer cell survival and proliferation. Indeed, in prostate cancer, activated ERK and Akt translocate to the nucleus, inducing various downstream effects (e.g., cell proliferation, migration, invasion and angiogenesis) (44). Furthermore, the activation of ERK1/2 promotes cell migration and invasion in prostate cancer cells $(37,45)$. Of note, in this study, QRFP significantly induced the migration and invasion of both PC3 and DU145 cells. The inhibition of the PI3K/Akt pathway significantly reduced the effects of QRFP (100 nM) on the migration of both PC3 and DU145 cells. On the other hand, the inhibition of MAPK/ERK with U0126 inhibited only partially the effect of QRFP, without reaching statistical significance. Although there was no effect of QRFP on cell proliferation, in a recent study by Ljujic et al (46), it was evident that the addition of both inhibitors to PC3 cells on their own significantly reduced cell viability. Similarly, in another study by Rybak et al (47), using DU145 cells, treatment with U0126 resulted in the reduction of cell propagation. Therefore, we could not exclude the direct effects of these two inhibitors. Future studies using a wider repertoire of inhibitors should provide a better insight into the involvement of MAPK and PI3K in these responses.

Notably the expression of MMPs is associated with the migration, invasiveness and metastatic potential of prostate cancer cell lines (48). Recent data have also indicated a connection between the ERK1/2 signalling activation and MMPs (49). Indeed, the upregulated expression of MMPs has been linked to MAPK (ERK, p38, JNK) and Akt pathways (50). Furthermore, it has been also shown that the p38 MAPK pathway is required for the TGF- $\beta$-mediated MMP2 induction and increased cell invasion in prostate cancer (51). In the present study, we focused primarily on MMP2, since an increase in its expression has been reported in prostate cancer and appears to correlate with a larger tumour size (52). A recent study indicated that the expression of MMP2 was observed in metastatic cancer, but not in micro-metastasis, strongly proposing that increased MMP2 expression was related with prostate cancer development and metastasis (53). However, we acknowledge that activated MMP2 can activate other MMPs, such as MMP-9 through enzymatic cleavage. Therefore, future studies are warranted to also concentrate on other MMPs, as well as the use of gelatin zymography to determine their effect.

It is plausible therefore, that the activation of MMP2 and the subsequent induction of cell invasion involved the MAPK/PI3K/Akt signalling pathways in accordance with the findings of the cell migration and invasion experiments in the present study. In the study by Ljujic et al, alpha-1-antitrypsin antagonized cisplatin-induced cytotoxicity in PC3 cells, an effect that was differentially mediated by ERK or Akt inhibitors (46). Furthermore, as displayed in Fig. 5, the effect of the inhibitors on QRFP and GPR103 expression was similar in terms of leptin inhibition, but in terms of cell migration, treatment with U0126 failed to reach statistical significance. It is possible therefore, that overlapping and distinct pathways are operating in these cells to perform specific functions. For example, there is an abundance of evidence that mTOR signalling is implicated in prostate cancer. Upstream of mTORC1, TSC1/TSC 2 complexes can be phosphorylated by either Akt or ERK1/2. Thus, there is a possibility of convergence of those two signalling pathways at this point. 
Finally, there are data indicating that obesity may be associated with a higher risk of advanced/aggressive prostate cancer, potentially through the effects of adipose-tissue derived factors/hormones, collectively termed adipokines (e.g,. leptin which constitutes the prototype adipokine) (54-57). Although available data on leptin and the expression of leptin receptor in human prostate and relevant prostate cell lines are contradictory, the existing evidence indicates that this pleiotropic, pro-inflammatory adipokine may exert varying effects on prostate cancer at different stages of its progression $(56,58)$. Of note, it has been revealed that in the androgen-resistant PC3 and DU145 prostate cancer cell lines, leptin can increase cell growth in a dose-dependent manner and induce ERK1/2 phosphorylation and JNK activation, whereas these leptin-induced effects are less prominent or absent in the androgen-sensitive LNCaP prostate cancer cells $(59,60)$. In the experiments of the present study, only leptin, but neither adiponectin nor chemerin, was demonstrated to significantly induce the gene expression of both QRFP and its cognate GP103 receptor in the PC3 androgen-independent prostate cancer cell line. Notably, recent data indicated that the leptin-induced stimulatory effects on the proliferative activity of prostate cancer cell lines depend on the expression of the variant 1 isoform of the leptin receptor (LEPR var 1; OB-R) (58). Previous data have also indicated that JNK mediated the leptin-stimulated cell proliferation of androgen-independent prostate cancer cells through STAT3 and Akt (61). In our experiments, we demonstrated that the inhibition of both the MAPK/ERK and PI3K/Akt pathways significantly abated the leptin-induced effect on the expression of QRFP and GPR103 in the androgen-independent PC3 prostate cancer cell line.

Collectively, the present study provided novel insight into the effects of QRFP in human prostate cancer. Our present findings also indicated that the adipokine, leptin, modulated the expression of QRFP and GPR103 in an androgen-independent human prostate cancer cell line via a PI3K- and a MAPK-dependent mechanism, thus providing a potential link between adiposity and prostate cancer.

\section{Acknowledgements}

Not applicable.

\section{Funding}

This study was funded by the UHCW NHS Trust and the Libyan Embassy in the UK.

\section{Availability of data and materials}

The datasets used and/or analyzed during the current study are available from the corresponding author on reasonable request.

\section{Authors' contributions}

HSR and EK were involved in the conception and design of the study. MABK was involved in the development of the methodology. MABK, MR, KW and JJ were involved in the acquisition of the data. MABK, HSR, EK and IK were involved in the analysis and interpretation of the data. HSR, EK and IK were involved in the writing, reviewing and/or revision of the manuscript. HSR supervised the study. All authors read and approved the final manuscript.

\section{Ethics approval and consent to participate}

The present study was approved by the National Research Ethics Committee and the hospital Research and Development department and was conducted according to the principles of good clinical practice and the recommendations of the Declaration of Helsinki. All patients who were recruited in the study provided informed written consent.

\section{Patient consent for publication}

Not applicable.

\section{Competing interests}

The authors declare that they have no competing interests.

\section{References}

1. Findeisen M, Rathmann D and Beck-Sickinger AG: RFamide peptides: Structure, function, mechanisms and pharmaceutical potential. Pharmaceuticals 4: 1248-1280, 2011.

2. Ukena K, Vaudry H, Leprince J and Tsutsui K: Molecular evolution and functional characterization of the orexigenic peptide $26 \mathrm{RFa}$ and its receptor in vertebrates. Cell Tissue Res 343: 475-81, 2011

3. Sandvik GK, Hodne K, Haug TM, Okubo K and Weltzien FA: RFamide peptides in early vertebrate development. Front Endocrinol 5: 203, 2014.

4. Chartrel N, Dujardin C, Anouar Y, Leprince J, Decker A, Clerens S, Do-Régo JC, Vandesande F, Llorens-Cortes C Costentin J, et al: Identification of $26 \mathrm{RFa}$, a hypothalamic neuropeptide of the RFamide peptide family with orexigenic activity. Proc Natl Acad Sci USA 100: 15247-52, 2003.

5. Bruzzone F, Lectez B, Tollemer H, Leprince J, Dujardin C, Rachidi W, Chatenet D, Baroncini M, Beauvillain JC, Vallarino M, et al: Anatomical distribution and biochemical characterization of the novel RFamide peptide 26RFa in the human hypothalamus and spinal cord. J Neurochem 99: 616-627, 2006

6. Takayasu S, Sakurai T, Iwasaki S, Teranishi H, Yamanaka A, Williams SC, Iguchi H, Kawasawa YI, Ikeda Y, Sakakibara I, et al: A neuropeptide ligand of the $\mathrm{G}$ protein-coupled receptor GPR103 regulates feeding, behavioral arousal, and blood pressure in mice. Proc Natl Acad Sci USA 103: 7438-7443, 2006.

7. Leprince J, Bagnol D, Bureau R, Fukusumi S, Granata R, Hinuma S, Larhammar D, Primeaux S, Sopkova-de Oliveiras Santos J, Tsutsui K, et al: The Arg-Phe-amide peptide 26RFa/glutamine RF-amide peptide and its receptor: IUPHAR Review 24. Br J Pharmacol 174: 3573-3607, 2017.

8. Jiang Y, Luo L, Gustafson EL, Yadav D, Laverty M, Murgolo N, Vassileva G, Zeng M, Laz TM, Behan J, et al: Identification and characterization of a novel RF-amide peptide ligand for orphan G-protein-coupled receptor SP9155. J Biol Chem 278: 27652-27657, 2003.

9. Fukusumi S, Yoshida H, Fujii R, Maruyama M, Komatsu H, Habata Y, Shintani Y, Hinuma S and Fujino M: A new peptidic ligand and its receptor regulating adrenal function in rats. $\mathrm{J}$ Biol Chem 278: 46387-46395, 2003

10. Baribault H, Danao J, Gupte J, Yang L, Sun B, Richards W and Tian H: The G-protein-coupled receptor GPR103 regulates bone formation. Mol Cell Biol 26: 709-717, 2006.

11. Moriya R, Sano H, Umeda T, Ito M, Takahashi Y, Matsuda M, Ishihara A, Kanatani A and Iwaasa H: RFamide peptide QRFP43 causes obesity with hyperphagia and reduced thermogenesis in mice. Endocrinology 147: 2916-2922, 2006.

12. Navarro VM, Fernández-Fernández R, Nogueiras R, Vigo E, Tovar S, Chartrel N, Le Marec O, Leprince J, Aguilar E, Pinilla L, et al: Novel role of $26 \mathrm{RFa}$, a hypothalamic RFamide orexigenic peptide, as putative regulator of the gonadotropic axis. J Physiol 573: 237-249, 2006. 
13. Patel SR, Murphy KG, Thompson EL, Patterson M, Curtis AE, Ghatei MA and Bloom SR: Pyroglutamylated RFamide peptide 43 stimulates the hypothalamic-pituitary-gonadal axis via gonadotropin-releasing hormone in rats. Endocrinology 149: 4747-4754, 2008.

14. Alonzeau J, Alexandre D, Jeandel L, Courel M, Hautot C, El Yamani FZ, Gobet F, Leprince J, Magoul R, Amarti A, et al: The neuropeptide $26 \mathrm{RFa}$ is expressed in human prostate cancer and stimulates the neuroendocrine differentiation and the migration of androgeno-independent prostate cancer cells. Eur J Cancer 49: 511-519, 2013.

15. Ørsted DD, Bojesen SE, Nielsen SF and Nordestgaard BG: Association of clinical benign prostate hyperplasia with prostate cancer incidence and mortality revisited: A nationwide cohort study of 3,009,258 men. Eur Urol 60: 691-698, 2011

16. Ervik M, Lam F, Ferlay J, Mery L, Soerjomataram I and Bray F: Cancer Today. Lyon, France: International Agency for Research on Cancer. Cancer Today 2016 Available from: http://gco.iarc. fr/today. Accessed January 22, 2018.

17. Ferlay J, Soerjomataram I, Dikshit R, Eser S, Mathers C, Rebelo M, Parkin DM, Forman D and Bray F: Cancer incidence and mortality worldwide: Sources, methods and major patterns in GLOBOCAN 2012. Int J Cancer 136: E359-E386, 2015.

18. Center MM, Jemal A, Lortet-Tieulent J, Ward E, Ferlay J, Brawlt $\mathrm{O}$ and Bray $\mathrm{F}$ : International variation in prostate cancer incidence and mortality rates. Eur Urol 61: 1079-1092, 2012.

19. Nelson EC, Cambio AJ, Yang JC, Ok JH, Lara PN Jr and Evans CP: Clinical implications of neuroendocrine differentiation in prostate cancer. Prostate Cancer Prostatic Dis 10: 6-14, 2007.

20. Foster HA, Davies J, Pink RC, Turkcigdem S, Goumenou A, Carter DR, Saunders NJ, Thomas P and Karteris E: The human myometrium differentially expresses mTOR signalling components before and during pregnancy: Evidence for regulation by progesterone. J Steroid Biochem Mol Biol 139: 166-172, 2014.

21. Johnson TR, Khandrika L, Kumar B, Venezia S, Koul S, Chandhoke R, Maroni P, Donohue R, Meacham RB and Koul HK: Focal adhesion kinase controls aggressive phenotype of androgen-independent prostate cancer. Mol Cancer Res 6 : 1639-1648, 2008.

22. Chen Y, Xin X, Li J, Xu J, Yu X, Li T, Mo Z and Hu Y: RTK/ERK pathway under natural selection associated with prostate cancer. PLoS One 8: e78254, 2013.

23. Li WH, Qiu Y, Zhang HQ, Tian XX and Fang WG: P2Y2 receptor and EGFR cooperate to promote prostate cancer cell invasion via ERK1/2 pathway. PLoS One 10: e0133165, 2015.

24. Ghosh PM, Malik SN, Bedolla RG, Wang Y, Mikhailova M, Prihoda TJ, Troyer DA and Kreisberg JI: Signal transduction pathways in androgen-dependent and -independent prostate cancer cell proliferation. Endocr Relat Cancer 12: 119-134, 2005.

25. McCubrey JA, Steelman LS, Abrams SL, Bertrand FE, Ludwig DE, Bäsecke J, Libra M, Stivala F, Milella M, Tafuri A, et al: Targeting survival cascades induced by activation of Ras/Raf/MEK/ERK, PI3K/PTEN/Akt/mTOR and Jak/STAT pathways for effective leukemia therapy. Leukemia 22: 708-722, 2008.

26. Tibbles LA and Woodgett JR: The stress-activated protein kinase pathways. Cell Mol Life Sci 55: 1230-1254, 1999.

27. Ricote M, García-Tuñón I, Fraile B, Fernández C, Aller P, Paniagua R and Royuela M: P38 MAPK protects agains TNF-alpha-provoked apoptosis in LNCaP prostatic cancer cells. Apoptosis 11: 1969-1975, 2006.

28. Koul HK, Pal M and Koul S: Role of p38 MAP Kinase signal transduction in solid tumors. Genes Cancer 4: 342-359, 2013

29. Lotan TL, Lyon M, Huo D, Taxy JB, Brendler C, Foster BA, Stadler W and Rinker-Schaeffer CW: Up-regulation of MKK4 MKK6 and MKK7 during prostate cancer progression: An important role for SAPK signalling in prostatic neoplasia. J Pathol 212: 386-394, 2007.

30. Magi-Galluzzi C, Mishra R, Fiorentino M, Montironi R, Yao H, Capodieci P, Wishnow K, Kaplan I, Stork PJ and Loda M: Mitogen-activated protein kinase phosphatase 1 is overexpressed in prostate cancers and is inversely related to apoptosis. Lab Invest 76: 37-51, 1997.

31. Boldt S, Weidle UH and Kolch W: The role of MAPK pathways in the action of chemotherapeutic drugs. Carcinogenesis 23 : 1831-1838, 2002

32. Xia Z, Dickens M, Raingeaud J, Davis RJ and Greenberg ME: Opposing effects of ERK and JNK-p38 MAP kinases on apoptosis. Science 270: 1326-1331, 1995.
33. Xu L, Chen S and Bergan RC: MAPKAPK2 and HSP27 are downstream effectors of p38 MAP kinase-mediated matrix metalloproteinase type 2 activation and cell invasion in human prostate cancer. Oncogene 25: 2987-2998, 2006.

34. Chen L, He HY, Li HM, Zheng J, Heng WJ, You JF and Fang WG: ERK1/2 and $\mathrm{p} 38$ pathways are required for P2Y receptor-mediated prostate cancer invasion. Cancer Lett 215: 239-247, 2004.

35. Gururajan M, Chui R, Karuppannan AK, Ke J, Jennings CD and Bondada S: c-Jun N-terminal kinase (JNK) is required for survival and proliferation of B-lymphoma cells. Blood 106: 1382-1391, 2005

36. Shimada K, Nakamura M, Ishida E, Kishi M, Yonehara S and Konishi N: c-Jun NH2-terminal kinase-dependent Fas activation contributes to etoposide-induced apoptosis in p53-mutated prostate cancer cells. Prostate 55: 265-280, 2003.

37. Rodríguez-Berriguete $G$, Fraile $B$, Martínez-Onsurbe $P$, Olmedilla G, Paniagua R and Royuela M: MAP kinases and prostate cancer. J Signal Transduct 2012: 169170, 2012.

38. Davis RJ: Signal transduction by the JNK group of MAP kinases. Cell 103: 239-252, 2000.

39. Sui X, Kong N, Ye L, Han W, Zhou J, Zhang Q, He C and Pan H: p38 and JNK MAPK pathways control the balance of apoptosis and autophagy in response to chemotherapeutic agents. Cancer Lett 344: 174-179, 2014

40. Guo J, Zhu T, Chen L, Nishioka T, Tsuji T, Xiao ZX and Chen CY: Differential sensitization of different prostate cancer cells to apoptosis. Genes Cancer 1: 836-846, 2010.

41. Shukla S, Maclennan GT, Hartman DJ, Fu P, Resnick MI and Gupta S: Activation of PI3K-Akt signaling pathway promotes prostate cancer cell invasion. Int J Cancer 121: 1424-1432, 2007.

42. Toren P and Zoubeidi A: Targeting the PI3K/Akt pathway in prostate cancer: Challenges and opportunities (Review). Int J Oncol 45: 1793-1801, 2014

43. Gan Y, Shi C, Inge L, Hibner M, Balducci J and Huang Y: Differential roles of ERK and Akt pathways in regulation of EGFR-mediated signaling and motility in prostate cancer cells. Oncogene 29: 4947-4958, 2010.

44. Yao Huang and Yongchang Chang: Epidermal Growth Factor Receptor (EGFR) Phosphorylation, Signaling and Trafficking in Prostate Cancer. Prostate Cancer-From Bench to Bedside. Dr. Philippe E. Spiess (ed). InTech, doi: 10.5772/27021, 2011.

45. Ding G, Fang J, Tong S, Qu L, Jiang H, Ding Q and Liu J: Over-expression of lipocalin 2 promotes cell migration and invasion through activating ERK signalling to increase SLUG expression in prostate cancer. Prostate 75: 957-968, 2015.

46. Ljujic M, Mijatovic S, Bulatovic MZ, Mojic $M$, Maksimovic-Ivanic D, Radojkovic D and Topic A: Alpha-1antitrypsin antagonizes cisplatin-induced cytotoxicity in prostate cancer (PC3) and melanoma cancer (A375) cell lines. Pathol Oncol Res 23: 335-343, 2017.

47. Rybak AP, Ingram AJ and Tang D: Propagation of human prostate cancer stem-like cells occurs through EGFR-mediated ERK activation. PLoS One 8: e61716, 2013.

48. Xiao LJ, Lin P, Lin F, Liu X, Qin W, Zou HF, Guo L, Liu W, Wang SJ and Yu XG: ADAM17 targets MMP-2 and MMP-9 via EGFR-MEK-ERK pathway activation to promote prostate cancer cell invasion. Int J Oncol 40: 1714-1724, 2012.

49. Moulik S, Pal S, Biswas J and Chatterjee A: Role of ERK in modulating MMP 2 and MMP 9 with respect to tumour invasiveness in human cancer cell line MCF-7 and MDA-MB-231. Journal of Tumor 2: 87-98, 2014.

50. Yang JL, Lin JH, Weng SW, Chen JC, Yang JS, Amagaya S, Funayana S, Wood WG, Kuo CL and Chung JG: Crude extract of Euphorbia formosana inhibits the migration and invasion of DU145 human prostate cancer cells: The role of matrix metalloproteinase-2/9 inhibition via the MAPK signaling pathway. Mol Med Rep 7: 1403-1408, 2013.

51. Huang X, Chen S, Xu L, Liu Y, Deb DK, Platanias LC and Bergan RC: Genistein inhibits p38 map kinase activation, matrix metalloproteinase type 2 , and cell invasion in human prostate epithelial cells. Cancer Res 65: 3470-3478, 2005.

52. Oguic R, Mozetič V, Cini Tešar E, Fučkar Čupić D, Mustać E and Dorđević G: Matrix metalloproteinases 2 and 9 immunoexpression in prostate carcinoma at the positive margin of radical prostatectomy specimens. Patholog Res Int 2014: 262195, 2014.

53. Trudel D, Fradet Y, Meyer F, Harel F and Têtu B: Significance of MMP-2 expression in prostate cancer: An immunohistochemical study. Cancer Res 63: 8511-8515, 2003. 
54. Kyrou I, Randeva HS and Weickert MO: Clinical Problems Caused by Obesity. In: De Groot LJ, Chrousos G, Dungan K, Feingold KR, Grossman A, Hershman JM, Koch C, Korbonits M, McLachlan R, New M, Purnell J, Rebar R, Singer F, Vinik A, editors. South Dartmouth (MA): MDText.com, Inc. 2014. Available on Endotext [Internet].

55. Kyrou I, Mattu HS, Chatha K and Randeva HS: Chapter 7-Fat Hormones, Adipokines. In Schisler JC, Lang CH, Willis MS (eds). Endocrinology of the Heart in Health and Disease. Academic Press 2017: 167-205, 2017.

56. Alshaker H, Sacco K, Alfraidi A, Muhammad A, Winkler M and Pchejetski D: Leptin signalling, obesity and prostate cancer: Molecular and clinical perspective on the old dilemma. Oncotarget 6: 35556-35563, 2015.

57. Baillargeon $\mathrm{J}$ and Rose DP: Obesity, adipokines, and prostate cancer (Review). Int J Oncol 28: 737-745, 2006.

58. Szyszka M, Tyczewska M, Milecka P, Jopek K, Celichowski P, Malendowicz LK and Rucinski M: Effects of leptin on leptin receptor isoform expression and proliferative activity in human normal prostate and prostate cancer cell lines. Oncol Rep 39: $182-192,2018$
59. Hoda MR, Theil G, Mohammed N, Fischer K and Fornara P: The adipocyte-derived hormone leptin has proliferative actions on androgen-resistant prostate cancer cells linking obesity to advanced stages of prostate cancer. J Oncol 280386, 2012.

60. Onuma M, Bub JD, Rummel TL and Iwamoto Y: Prostate cancer cell-adipocyte interaction: Leptin mediates androgen-independent prostate cancer cell proliferation through c-Jun NH2-terminal kinase. J Biol Chem 278: 42660-42667, 2003.

61. Miyazaki T, Bub JD and Iwamoto Y: c-Jun $\mathrm{NH}_{2}$-terminal kinase mediates leptin-stimulated androgen-independent prostate cancer cell proliferation via signal transducer and activator of transcription 3 and Akt. Biochim Biophys Acta 1782: 593-604, 2008.

This work is licensed under a Creative Commons Attribution 4.0 International (CC BY 4.0) License. 